\title{
Combined Effects of Occupational Noise Exposure and Shiftwork on Performance Tasks in a Seafaring Population
}

\author{
Ben Wellens, PhD, Rachel McNamara, PhD, Neil Ellis,MSc, Andrew Smith, PhD* \\ Centre for Occupational and Health Psychology, School of Psychology, Cardiff University, 63 Park Place, \\ Cardiff, CF10 3AS, Wales, UK.
}

*Corresponding Author: Andrew Smith, PhD, Centre for Occupational and Health Psychology, School of Psychology, Cardiff University, 63 Park Place, Cardiff, CF10 3AS, Wales, UK.

\begin{abstract}
This study was undertaken to complement a cross-sectional survey of the combined effects of selfreported workplace stressors. Data were collected from seafarers on board support vessels for the North Sea oilrigs as part of a project on offshore fatigue. These data could also be used specifically to address whether there were any cognitive effects associated with working in loud noise at night that were different to working in loud noise during the day, low noise at night or low noise during the day. The participants were 62 male workers from 3 different vessels. Their mean age was 40.3 years. Individuals were from a range of different jobs onboard the vessels. There were two between-subjects factors (day/night shift and noise exposure) and one within-subjects factor (test session). Workers were asked to complete a battery of computer tests both before (Pre-shift) and after (Post-shift) their shift on one day. Four tests were presented using laptop computers. These tests were visual analogue mood scales, a simple variable fore-period reaction time, and categoric search and focused attention choice reaction time tasks. The mood scales were presented at the beginning and end of the testing session. Occupational noise exposure (Leq) was measured over a two-day period using a dosimeter. Workers were categorised into day/night workers by their shift pattern. Regression analyses distinguishing noise exposure, day/night shift and their interaction were performed on the data from each test session and the change score between the start and end of the shift. Noise exposure was associated with increased alertness but also with slower reaction times. Those working night shifts showed a large drop in alertness over the course of work and became slower at tasks requiring more difficult responses. There were also a limited number of interactions between noise and shift, such as more lapses of attention (very long response times) but fewer incorrect responses in the noise/night-work condition. The findings suggest that these techniques may provide valuable information about the possible combined effects of occupational stressors in situ. The present analyses are based only on a small number of night workers and further consideration of effects of potential confounding influences must also be undertaken.
\end{abstract}

Key words: Noise, Shiftwork, Seafarers, Performance, Mood.

\section{INTRODUCTION}

There has been previous research on a large number of workplace hazards. These include those arising from the psychosocial environment as well as those due to working hours and physical agents. For the most part the nature and effects of these are considered in isolation. This is not often representative of the real-life situation where employees are likely to be exposed to multiple hazards (e.g. noise, shiftwork, organic solvents). There is limited information on the combined effects of these hazards on health and performance efficiency. Indeed, there have not even been any systematic reviews of the existing literature, no attempt to produce a coherent framework for studying these factors, and a dearth of studies using multi-methods to investigate the topic. However, in many industries it is crucial to consider the combinations of factors the worker is exposed to (Smith and Mackay, 2001). This is particularly true for seafarers as high-lighted by the following quote:

"Global concern with the extent of seafarer fatigue and the potential environmental costs is widely evident everywhere in the shipping industry. Maritime regulators, ship owners, trade unions and $P \& I$ clubs are all alert to the fact that in some ship types, a combination of minimal manning, sequences of rapid turnarounds and short sea passages, adverse weather and traffic conditions, may find seafarers working long hours and with insufficient recuperative rest. In these circumstances fatigue and reduced performance may lead to environmental damage, ill-health and reduced life-span among highly skilled 
seafarers who are in short supply. A long history of research into working hours and conditions and their performance effects in manufacturing and process industries as well as in road transport and civil aviation, has no parallel in commercial shipping" (Smith, Lane and Bloor, 2000).

Previous research has investigated combined effects of workplace stressors on seafarers' health (McNamara and Smith, 2020). They found that it was the combination of work-related factors that influenced self-reported health in seafarers. However, the extent to which this environment, and the combination of specific factors within this environment, has a measurable impact on performance has not been investigated. This may to some extent reflect the difficulties encountered in measuring occupational performance. One method that has been used to examine this topic is to use interpolated artificial tasks to make inferences about changes in performance over the day. This approach has been used successfully to examine the effects of fatigue and noise (Broadbent, 1979), working hours (Monk and Folkard, 1985) and. workload (Parkes, 1995). Similarly, such measures are sensitive to healthrelated behaviours (e.g. ingestion of caffeine - Brice \& Smith, 2001) and health status (e.g. upper respiratory tract illnesses- Smith et al., 2000).

The present study investigated single and combined effects of occupational stressors aboard ship. Stressful aspects of offshore work are represented in the present investigation by two factors, both which were objectively measured (a) time of shift and (b) noise level. These were chosen for a number of reasons:

(1) The independent performance effects of noise (see Smith and Jones, 1992 for a review) and time of day effects (see Smith, 1992 for a review) are well known.

(2) The performance effects of noise and circadian variation have been previously studied in the laboratory (Smith and Miles, 1986, 1987a and 1987b), and the present study offered an opportunity to compare effects in the real-life context. These studies showed that noise and night-work had selective effects on performance. Indeed, even where the two factors influenced the same dependent variable (e.g. alertness), effects were independent not interactive.

(3) To complement studies of the associations of self-reported occupational noise exposure and exposure to temporal stressors with physical and mental health outcomes (Smith et al., 2001).

(4) These measures could be easily taken without interfering with the ongoing work of the volunteers.

\section{MATERIAL AND MethodS}

\subsection{Sample}

62 working volunteers from various occupations on-board 3 vessels serving the offshore oil industry.

\subsection{Measures}

Participants were required to complete a battery of computerised performance and mood tasks on a laptop computer, in the same order, before and after work on one day of their shift.

\subsubsection{Mood}

Ratings of mood were taken using visual analogue mood scales. Participants were presented with 18 scales comprising a pair of adjectives anchored at either end of a linear scale - e.g. drowsy - alert. Participants were asked to move the display pointer, using the keys on a response box, to a position on the scale that was representative of their mood. Three main factors were then extracted from the results: alertness, anxiety and hedonic tone.

\subsubsection{Simple Reaction Time (SRT)}

A white frame was displayed in the centre of the screen and at varying intervals (1-8 seconds) a solid white square appeared inside the frame. Participants were asked to press a response key as soon as they detected the solid square. This task lasted approximately 3 minutes. Mean reaction times were calculated for the test as a whole, as well as for each minute of the task.

\subsubsection{Focused Attention}

(Broadbent et al, 1989): Target letters (A's or B's) were presented at random intervals in the centre of the screen. The target stimulus was shown on its own, with an asterisk on either side, or with a letter 
either side. Participants were required to ignore any distracters presented in the periphery and respond to the target stimuli only. This task measures mean reaction time, accuracy of response (percent correct), lapses of attention (occasional long responses), the Eriksen effect (which measures the focusing of attention) and speed of encoding information (i.e. reaction time differences between conditions when target is alternated/repeated from a previous trial).

\subsubsection{Categoric Search}

(Broadbent et al., 1989): This task is similar to the focused attention task outlined above. Prior to the presentation of the target letter, two crosses were shown either in the centre of the screen or towards the extreme left and right of the screen. The target letter, either A or B, then appeared in place of one of these crosses. For half the trials the target letter was presented alone and for the other half it was accompanied by a distracter digit. Reaction time, response accuracy, lapses of attention, spatial uncertainty (i.e. the extent to which knowing the target location affects accuracy and reaction time), speed of encoding and the effect of target location (i.e. difference in reaction times between targets presented in different/same location) were measured. In addition, trials differed in stimulus-response compatibility (on some trials the stimulus appeared on the same side of the screen as the hand with which the response had to be made (compatible condition), on others it appeared on the opposite side of the screen (incompatible condition).

\subsection{Noise}

Noise was measured using dosimetry. Noise was measured in $\mathrm{dB}(\mathrm{A})$ and the 'equivalent continuous' level (Leq) is quoted.

\subsection{Timing of Shift}

Timing of shift was defined by usual shift patterns. The length of the shift was 12 hours from 18:00 06:00 for night workers and 06:00 - 18:00 for day workers.

\subsection{Analysis}

Stepwise regression analyses were carried out in SPSS with the mood and performance measures as dependent variables. Noise exposure (Leq) was included in the regression model as a continuous predictor variable and shift type (day or night) as a categorical predictor variable. Therefore the two between-subjects factors were (a) objectively measured noise exposure and (b) day/night shift. The interaction of the two predictors was also included in the model.

\section{Results}

\subsection{Demographics}

The sample consisted of 62 men working in different capacities aboard vessels associated with the offshore oil industry. The mean age of the sample was 40.3 years $(\mathrm{SD}=9.41)$ with the youngest being 21 years old and the oldest 58 years old. The majority were British/Irish $(83.9 \%)$, with a smaller number being European (12.9\%) and 'other' (3.2\%) respectively. Participants held an array of occupational roles aboard the vessels. 9 (14.5\%) were marine officers, 13 (21.0\%) non-marine crew (e.g. divers), 37 (59.7 $\%)$ marine crew (i.e. steward, cook, medic) and 3 (4.8\%) had missing data for job title.

Of the 62 workers, $53(85.5 \%)$ were day workers and only $9(14.5 \%)$ were night workers. The night workers were marginally older (41.3 years old) than day workers (40.1 years old) on average. Also night workers were drawn from a specific subset of occupations onboard the vessels, exclusively from the non-marine crew. Aside from differences in occupations of day and night workers, there were also significant differences in the organisation of their work. The majority of both day- and night- workers worked 28 day tours of duty, however amongst the day workers there were more people working tours of duty both shorter (14 -21 days) and longer than this (30 - 56 days). Also, at the time of testing, night workers generally had been on tour for less time ( $<14$ days), whereas a substantial proportion of day workers had been on tour $>15$ days.

On average, day workers were exposed to slightly greater noise, as would be expected given the greater general activity on board during the day (Noise (Leq): Day shift: Mean 62.1 dB, s.d. 6.49, Min 55.2, Max 72.5; Night shift: Mean 57.9 dB, s.d. 4.58, Min 55.2, Max 69.3). For the tabulated comparisons of means in the results, objectively measured noise exposure was split into high $(>59 \mathrm{~dB}(\mathrm{a}))$ and low $(<59$ 
$\mathrm{dB}(\mathrm{a}))$ noise exposure. For the analyses presented below this meant that there were considerably unequal cell sizes $(<59 \mathrm{~dB}$ : Day workers $=22$; Night workers $=6 ;>59 \mathrm{~dB}$ : Day workers $=31$, Night workers $=3$ ).

\section{Mood and Performance Results}

Results are shown according to the type of effect observed: (a) main effects of noise, (b) main effects of shift, and (c) interactions between noise and shift.

\subsection{Noise exposure}

There were a considerable number of main effects of noise. These effects are summarised below, grouped by test. Where there were main effects of noise, the effect was almost always present both preand post-shift. This suggests that the effects were chronic, not reflecting exposure to noise over the shift but more general, longer term, exposure.

\subsubsection{Mood}

Noise had a significant effect on mood (Table 1). Increased noise was associated with increased reported alertness and increased hedonic tone (i.e. more 'happiness'). There was also a main effect on post-shift reported anxiety, which decreased.

Table1. Noise and mood (higher scores = greater alertness, hedonic tone and calm)

\begin{tabular}{|l|l|l|l|}
\hline & $<59 \mathrm{~dB}(\mathrm{~A})(\mathrm{N}=28)$ & $>59 \mathrm{db}(\mathrm{a})(\mathrm{N}=33)$ & Significance \\
\hline Pre-shift alertness & Mean: $237 \mathrm{sd}=52$ & Mean=291 sd=62 & $\mathrm{t}=3.11 \mathrm{p}<0.01$ \\
\hline Post-shift alertness & Mean $=235 \mathrm{sd}=50$ & Mean $=288 \mathrm{sd}=63$ & $\mathrm{t}=4.41 \mathrm{p}<0.001$ \\
\hline Pre-shift hedonic tone & Mean $=187 \mathrm{sd}=41$ & Mean=222 sd=48 & $\mathrm{t}=3.46 \mathrm{p}<0.01$ \\
\hline Post-shift hedonic tone & Mean $=182 \mathrm{sd}=40$ & Mean $=219 \mathrm{sd}=49$ & $\mathrm{t}=4.07 \mathrm{p}<0.001$ \\
\hline Post-shift anxiety & Mean $=85.7 \mathrm{sd}=16.9$ & Mean $=100.2 \mathrm{sd}=26$ & $\mathrm{t}=2.33 \mathrm{p}<0.05$ \\
\hline
\end{tabular}

\subsubsection{Simple reaction time}

There was an increased post-shift mean reaction time on the simple reaction time task for those exposed to the higher noise levels $(<59 \mathrm{~dB}(\mathrm{~A})$ : mean $\mathrm{RT}=289 \mathrm{msec}, \mathrm{sd}=49 ;>59 \mathrm{db}(\mathrm{A})$ : mean $\mathrm{RT}=314 \mathrm{msec}$, s.d. $=56 ; t=2.27 p<0.05)$. Given that this was not apparent pre-shift this could reflect an acute effect of noise exposure.

\subsubsection{Focused attention task}

There were a number of significant noise effects (Table 2). Mean reaction time was slower in noise on both pre- and post-shift measures, as were the number/percentage of long responses made. Also there was a significant main effect of noise on both pre- and post-test Eriksen effect measures, suggesting less focused attention pre-shift in those exposed to higher noise levels, but more focused attention in noise post-shift.

Table2. Effects of noise on the focused attention choice reaction time task

\begin{tabular}{|l|l|l|l|}
\hline & $<59 \mathrm{db}(\mathrm{A})(\mathrm{N}=28)$ & $>59 \mathrm{~dB}(\mathrm{~A})(\mathrm{N}=34)$ & Significance \\
\hline Pre-shift RT $(\mathrm{msec})$ & Mean=455 sd=54 & Mean=498 sd=66 & $\mathrm{t}=3.03 \mathrm{p}<0.01$ \\
\hline Post-shift RT (msec) & Mean=440 sd=47 & Mean=477 sd=69 & $\mathrm{t}=3.21 \mathrm{p}<0.01$ \\
\hline $\begin{array}{l}\text { Pre-shift Eriksen effect } \\
(\mathrm{msec})\end{array}$ & Mean=3.7 sd=37 & Mean=21.0 sd=45 & $\mathrm{t}=2.80 \mathrm{p}<0.01$ \\
\hline $\begin{array}{l}\text { Post-shift Eriksen effect } \\
(\mathrm{msec})\end{array}$ & Mean=14.7 sd=39 & Mean=8.7 sd=36 & $\mathrm{t}=2.64 \mathrm{p}, 0.05$ \\
\hline $\begin{array}{l}\text { Pre-shift long responses } \\
(\mathrm{N})\end{array}$ & Mean=1.9 sd=2.2 & Mean=4.5 sd=5.8 & $\mathrm{t}=2.36 \mathrm{p}<0.05$ \\
\hline $\begin{array}{l}\text { Post-shift } \\
\text { responses }\end{array}$ & Mean=1.3 sd=2.1 & Mean=3.0 sd=5.8 & $\mathrm{t}=2.82 \mathrm{p}<0.01$ \\
\hline
\end{tabular}

\subsubsection{Categoric search task}

The analyses of the data from the categoric search task confirmed that noise exposure was associated with slower reaction times both pre- and post- shift 
(Pre-shift: $<59 \mathrm{~dB}(\mathrm{~A})$ : mean $=540 \mathrm{msec}, \mathrm{sd}=66 ;>59 \mathrm{~dB}(\mathrm{~A})$ : mean $=602, \mathrm{sd}=78 ; \mathrm{t}=2.78 \mathrm{p}<0.01$; Post-shift: $<59 \mathrm{~dB}(\mathrm{~A})$ : mean $=522 \mathrm{msec}, \mathrm{sd}=55 ;>59 \mathrm{~dB}(\mathrm{~A})$ : mean $=575, \mathrm{sd}=70 ; \mathrm{t}=2.88 \mathrm{p}<0.01$ ).

\subsection{Day/Night shift}

\subsubsection{Mood}

There were far fewer effects of day versus night shift probably reflecting the small number of night shift workers. There was a significant decrease in reported alertness between pre- and post-shift measurement, with alertness declining substantially for those working nights but increasing for those working days (alertness change: Day: mean $=7.4 \mathrm{sd}=57$; Night: mean $=-48.9 \mathrm{sd}=64.2 ; \mathrm{t}=2.68 \mathrm{p}<$ $0.05)$.

\subsubsection{Performance}

There were no effects of shift on the simple reaction time and focused attention tasks. On the more difficult categoric search task there were two significant change scores; mean reaction time increased in those working night shifts (especially on more difficult [incompatible] conditions) and there was a significant increase in the number/percentage of long responses made in the night group.

\subsection{Noise $x$ time of day}

There were no significant interactions in the analyses of mood, simple reaction time or focused attention data. All significant interactions were in the categoric search task. The profile of results suggested that the combined noise and night condition was associated with slower but more accurate responses (Table $3)$.

Table3. Noise $x$ shift interactions in categoric search task

\begin{tabular}{|c|c|c|c|c|c|}
\hline & $\begin{array}{l}\text { Day/Quiet } \\
(\mathrm{n}=22)\end{array}$ & $\begin{array}{l}\text { Day/Noise } \\
(\mathrm{N}=31)\end{array}$ & $\begin{array}{l}\text { Night/Quiet } \\
(\mathrm{N}=6)\end{array}$ & $\begin{array}{l}\text { Night/Noise } \\
(\mathrm{N}=3)\end{array}$ & Significance \\
\hline $\begin{array}{l}\text { Post-pre change } \\
\text { in RT }(\mathrm{msec})\end{array}$ & $\begin{array}{l}\text { Mean= } \\
-23.8 \\
\mathrm{sd}=28.6\end{array}$ & $\begin{array}{l}\text { Mean }= \\
-26.4 \\
\mathrm{sd}=34.2\end{array}$ & $\begin{array}{l}\text { Mean= } \\
-2.4 \\
\mathrm{sd}=28.3\end{array}$ & $\begin{array}{l}\text { Mean= } \\
3.8 \\
\mathrm{sd}=3.8\end{array}$ & $\begin{array}{l}F(1,61)=9.67 \\
P<0.01\end{array}$ \\
\hline $\begin{array}{l}\text { Post-shift long } \\
\text { RTs } \\
(>1000 \text { msecs })\end{array}$ & $\begin{array}{l}\text { Mean }=1.8 \\
\mathrm{sd}=1.9\end{array}$ & $\begin{array}{l}\text { Mean=3.5 } \\
\mathrm{sd}=4.8\end{array}$ & $\begin{array}{l}\text { Mean=2.8 } \\
\mathrm{sd}=4.0\end{array}$ & $\begin{array}{l}\text { Mean }=13.0 \\
\mathrm{sd}=14.2\end{array}$ & $\begin{array}{l}F(1,61)=6.86 \\
P<0.05\end{array}$ \\
\hline Post-shift errors & $\begin{array}{l}\text { Mean=5.8 } \\
\mathrm{sd}=3.4\end{array}$ & $\begin{array}{l}\text { Mean=4.7 } \\
\mathrm{sd}=4.4\end{array}$ & $\begin{array}{l}\text { Mean=3.2 } \\
\mathrm{sd}=3.2\end{array}$ & $\begin{array}{l}\text { Mean=1.4 } \\
\mathrm{sd}=1.5\end{array}$ & $\begin{array}{l}F(1,61)=5.52 \\
p<0.05\end{array}$ \\
\hline Post-pre errors & $\begin{array}{l}\text { Mean=1.6 } \\
\mathrm{sd}=2.4\end{array}$ & $\begin{array}{l}\text { Mean=1.6 } \\
\mathrm{sd}=2.8\end{array}$ & $\begin{array}{l}\text { Mean=1.7 } \\
\mathrm{sd}=2.9\end{array}$ & $\begin{array}{l}\text { Mean }=-1.7 \\
\mathrm{sd}=0\end{array}$ & $\begin{array}{l}F(1,61)=11.55 \\
p<0.001\end{array}$ \\
\hline
\end{tabular}

\subsection{Summary of results}

There were a large number of main effects of objectively measured noise exposure on mood and performance. Noise was associated with a greater alertness but slower reaction times. Those working night shifts showed a large drop in alertness over the course of work and became slower at tasks requiring greater organisation of the response (i.e. trials involving incompatible responses). There were also a limited number of interactions between noise exposure and day/night shift, such as (a) slower reaction times and more lapses in attention - as signified by long response times on the categoric search task -and (b) fewer incorrect responses in the noise/night condition.

\section{DISCUSSION}

The results from the present study suggest that both noise and shiftwork influence mood and performance, but there are few effects that present themselves as interactions between the two factors. However, there is some suggestion of specific areas of cognitive performance where the stressors in combination have a greater influence. Specifically, the combination of noise and night-work was associated with slower responses and more lapses of attention in the categoric search task, but also more accurate responding. In other words, the combined condition showed a change in the speed-error tradeoff function, an effect often associated with increased fatigue.

The general profile of individual effects of noise and night-work supports those reported in the 
literature. For example, noise increased alertness, as in the Smith and Miles (1986) study. Similarly, it increased the frequency of occasional long reaction times which is in agreement with studies cited by Broadbent (1979). As in laboratory studies (Smith and Miles, 1986; 1987a, 1987b) noise and nightwork were found to have largely selective and independent effects. The effects of night-work were less obvious, although alertness was found to decline more rapidly over the night shift than the day shift. The absence of other effects of working at night may reflect the small sample size. Indeed, analyses of a larger sample of seafarers working at night (Smith, Lane and Bloor, 2002) showed that their reaction times also slowed over the course of the shift. However, there was also some sign of adaptation to nightwork, with those who had been working nights for more than 5 days showing fewer impairments than those who were less than 5 days into their tour of duty.

It is worth considering the number of analyses that we would expect to be significant by chance (i.e. approximately 5\%). $34.8 \%$ of the 66 analyses were significant. $21.2 \%$ showed main effects of noise, $6.1 \%$ showed main effects of day/night shift and $7.6 \%$ were interaction between noise and day/night shift. The noise effects seem robust and a number of the other effects were both intuitive and highly significant. Others, however, could be chance effects and replication is desirable.

The research methodology described here provides a potential technique for examining combinations of stressors within a specific occupational environment. However, the present results must be treated with caution for a number of reasons. First, the number of night-workers was small. Secondly, the issue of other potentially confounding influences requires more detailed consideration. As was highlighted earlier volunteers were from three different vessels, and night workers were exclusively recruited from just one of these vessels, a dive support vessel. Therefore, there were obviously some unmeasured, and uncontrolled for, variables that may explain at least some of the present findings.

\section{ACKNOWLEDGEMENT}

This research was funded by the Maritime and Coastguard Agency and Health and Safety Executive (HSE). We would like to thank the ship owners who allowed access to their vessels and the volunteers who participated in the study.

\section{REFERENCES}

[1] Brice, C.F. \& Smith, A.P. 2001. The effects of caffeine on simulated driving, subjective alertness and sustained attention. Hum Psychopharmacol 16, 523 - 531.

[2] Broadbent, D.E. 1979. Is a fatigue test now possible? Ergonomics 22, 1277-1290.

[3] Broadbent, D.E. 1979. Human performance and noise. In C.S.Harris (ed), Handbook of Noise Control. New York: McGraw Hill.

[4] Broadbent, D.E., Broadbent, M.H.P. \& Jones, J.L. 1989. Time of day as an instrument for the analysis of attention. Eur J Cog Psy 1 (1): 69 - 94.

[5] McNamara, R.L. \& Smith, A.P. 2020. Combined effects of fatigue indicators on the health and wellbeing of workers in the offshore oil industry. Journal of Health and Medical Sciences.

[6] Monk, T.H. \& Folkard, S. 1983. Shiftwork and performance. In S. Folkard and T.H. Monk (eds), Hours of Work: Temporal Factors in Work Scheduling. Chichester: Wiley. pp 239- 252.

[7] Parkes, K.R. 1995. The effects of objective workload on cognitive performance in a field setting: A twoperiod cross-over trial. App Cog Psy, 9: 153- 171.

[8] Smith, A.P. 1992. Time of Day and Performance. In: Handbook of Human Performance. Volume 3: State and Trait. Smith, A.P. \& Jones, D.M. (eds), Academic Press, London. pp 217- 236.

[9] Smith, A.P., Brice, C.F., Sivell, S., Wadsworth, E. \& Wellens, B. 2001. Combined effects of occupational factors on objective measures of performance and health. In: Contemporary Ergonomics 2001. MA Hanson (ed), Taylor \& Francis, London. pp 203- 208.

[10] Smith, A.P., Brice, C.F., Sivell, S. \& Wellens, B. 2001. The combined effects of occupational factors on subjective reports of health. In: Contemporary Ergonomics 2001. MA Hanson (ed), Taylor \& Francis, London. pp $197-202$.

[11] Smith, A.P. \& Jones, D.M. (1992). Noise and Performance. In: Handbook of Human Performance. Volume 1: The Physical Environment Jones, DM and Smith, AP (ed), Academic Press Limited, London. pp $1-28$. 
[12] Smith, A.P., Lane, A.D. \& Bloor, M. 2002. Fatigue Offshore: A comparison of offshore oil support shipping and the offshore oil industry. SIRC Technical Report Series, ISBN No: 1-900174-14-6.

[13] Smith, A.P. \& Mackay, C. 2001 Combined effects of occupational health hazards. In: Contemporary Ergonomics 2001. M. Hanson (ed). London: Taylor \& Francis, London. pp 179-184.

[14] Smith, A.P. \& Miles, C. 1986. The combined effects of night-work and noise on human function. In: Night and Shiftwork: Long term effects and their prevention. Haider, M, Koller, M. \& Cervinka, R. (eds), Peter Lang, Frankfurt. pp $331-338$.

[15] Smith, A.P. \& Miles, C. 1987. Sex differences in the effects of noise and night-work on performance efficiency. Work \& Stress, 1(4): 333- 339.

[16] Smith, A.P. \& Miles, C. 1987. The combined effects of occupational health hazards: An experimental investigation of the effects of noise, night-work and meals. Int Arch Occup Environ Health, 59:, 83 - 89.

[17] Smith, A.P., Thomas, M. \& Whitney, H. 2000. Effects of upper respiratory tract illnesses on mood and performance over the working day. Ergonomics, 43, $752-763$.

Citation: Andrew Smith, PhD., et.al., " Combined Effects of Occupational Noise Exposure and Shiftwork on Performance Tasks in a Seafaring Population" International Journal of Humanities Social Sciences and Education (IJHSSE), vol 7, no. 7, 2020, pp. 150-156. doi: http://dx.doi.org/10.20431/2349-0381.0707017.

Copyright: (c) 2020 Authors. This is an open-access article distributed under the terms of the Creative Commons Attribution License, which permits unrestricted use, distribution, and reproduction in any medium, provided the original author and source are credited. 